\title{
Hydrological Response of Land Use Land Cover Change on Stream Flow of Anger Watershed, Blue Nile Basin, Ethiopia
}

\section{Getachew Rabo}

Hydraulic and Water Resources Engineering Department, College of Engineering and Technology, Wollega University, Nekemte, Ethiopia

Email address:

rabo.getachew11@gmail.com

\section{To cite this article:}

Getachew Rabo Hydrological Response of Land Use Land Cover Change on Stream Flow of Anger Watershed, Blue Nile Basin, Ethiopia. Journal of Civil, Construction and Environmental Engineering. Vol. 6, No. 3, 2021, pp. 92-103. doi: 10.11648/j.jccee.20210603.12

Received: May 4, 2021; Accepted: July 7, 2021; Published: July 21, 2021

\begin{abstract}
Stream flow of Anger watershed $\left(7,982 \mathrm{~km}^{2}\right)$, located in Western Oromia Regional State, Ethiopia was simulated by using soil and water assessment tool (SWAT) model. Assessment of layer staking, mosaicking, image classification and accuracy was carried by ArcGIS. The main target of this study was to determine the SWAT Model applicability and impact of past land-use land-cover change on stream flow of the Anger watershed. The time series data from 1990 to 1999 was used for model parameter calibration, and data from 2000 to 2004 were used to validate the model using the input parameter set. The performance of the SWAT model was evaluated by both $\mathrm{R}^{2}$ time series plots and ENS the statistical measures. The results of the model during calibration for monthly stream flow was $\mathrm{R}^{2}=0.90$, $\mathrm{ENS}=0.76$ and during validation $\mathrm{R}^{2}=0.84$, ENS $=0.63$ respectively. Validation of image classification is achieved through Mosaicking image and Google Earth image. The performance of the Arc GIS model was evaluated by using the overall accuracy and kapa coefficient. The agreement between classified land use image and ground truth of the year 1986, 2000 and 2010 were showed a good agreement with result of overall accuracy $=88 \%, 85 \%$ and $87 \%$ and kapa coefficient $=81 \%, 79 \%$ and $82 \%$ respectively. Simulation of steam flow of the watershed under the impacts of past land-use land-cover changes can be determined by using SWAT model as a tool for water resources planning and management in this watershed.
\end{abstract}

Keywords: SWAT Model, Arc GIS, Land-Use Land-Cover, Stream Flow, Anger Watershed

\section{Introduction}

Water resources are currently under severe pressure because of impacts of climate change and human activities, which include land-use land-cover change, increasing population growth, and economic development [1]. Assessing water resources becomes a complex task that must consider many aspects, of which climate and land-use land-cover change and variability are identified as key factors [2]. Whereas land-use land-cover change can cause changes in hydrological components in a sub watershed, such as evapotranspiration, stream flow and groundwater. Thus, separating the effects of climate and land-use land-cover changes on stream flow is important to produce accurate predictions of stream flow simulation and to provide useful information to land-use planning and water resources management [3]. Semi-distributed hydrological models, which use input parameters directly representing land surface characteristics, have been applied to assess the impact of land-use land-cover change on stream flow in water resource management areas [4].

Some research findings identified that, land-use land-cover change was the main driving factors for the decrease or increase in stream flow simulation. In Anger sub watershed, there is no studies considering land-use land-cover change have been performed in the sub watershed, therefore, this research focus on stream flow simulation under the impact of land-use land-cover change in Anger sub watershed. Hence, Anger sub watershed stream flow simulation under impact of land-use land-cover change was particularly important in improving water management efficiency and benefiting various water use needs such as irrigation and small-scale hydro power on Anger sub watershed. The overall objective of this study is to model stream flow under the impact of land-use land-cover change by using SWAT model. The specific objectives are: (1) to calibrate and validate SWAT model for study area (2) to quantify the effect of past landuse land-cover change on stream flow of sub watershed 
through scenario simulation. This study provides important information that decision-makers will need in order to assist with water resources management in the Anger sub watershed under changing land-use/ land-cover conditions.

\section{Materials and Methods}

\subsection{Description of the Study Area}

The Anger sub watershed is located in the East Wollega Zone, Oromia Regional State, Ethiopia, between latitudes $10.95^{\circ} \mathrm{N}$ to $11.80^{\circ} \mathrm{N}$ and longitudes $36.70^{\circ} \mathrm{E}$ to $37.40^{\circ} \mathrm{E}$ (Figure 1). The sub watershed has an area of 7,982 $\mathrm{km}^{2}$ and covers parts of fifteen woredas, namely: - Wayu Tika, Bila Seyo, Sibu Sire, Guto Gida, Sasiga, Gudaya Bila, Bilo Jegonfoy, Abe Dongoro, Horo, Gida Kiremu, Yaso, Limu, Haro, Jarti Jadeja, and Amuru. The climate of the Anger watershed is 'tropical highland monsoon' with an average annual rainfall of 1,604 $\mathrm{mm}$. Most of the rain falls during the months of June to September with peaks occurring during July to August and it is virtually dry from November through to April. As the watershed is located in a high rainfall area, it receives frequent torrential showers and frequent flash floods during the rainy season. The mean monthly maximum and minimum temperature of the area varies from 22 to $30^{\circ} \mathrm{C}$ and 11 to $15^{\circ} \mathrm{C}$ respectively (Figure 2).

The major landform of the watershed includes flat to gently sloping, undulating plains, hills and mountains. The western part of the watershed is characterized by highly rugged, mountainous and rolled topography with steep slopes and the lower part is characterized by a valley floor with flat to gentle slopes. Elevation in the watershed varies from 868 to $3,144 \mathrm{~m}$ above mean sea level. The major portion of the watershed is under intensive cultivation and maize, barley and wheat are the major crops grown in the watershed. Shrub land, grazing land, forest, woodland and wetland/swamp are other land cover types in the watershed.

The catchment has a wide range of soil types mainly dominated by Haplic Alisosls, Haplic Acirisols, Rahodic Nitisols and Dystiric Leptosols. The largest portion of the watershed is characterized by Haplic Alisosls. And also; Haplic Nitisols, Eutric Vertisols and Eutiric Regosols were part of watershed.

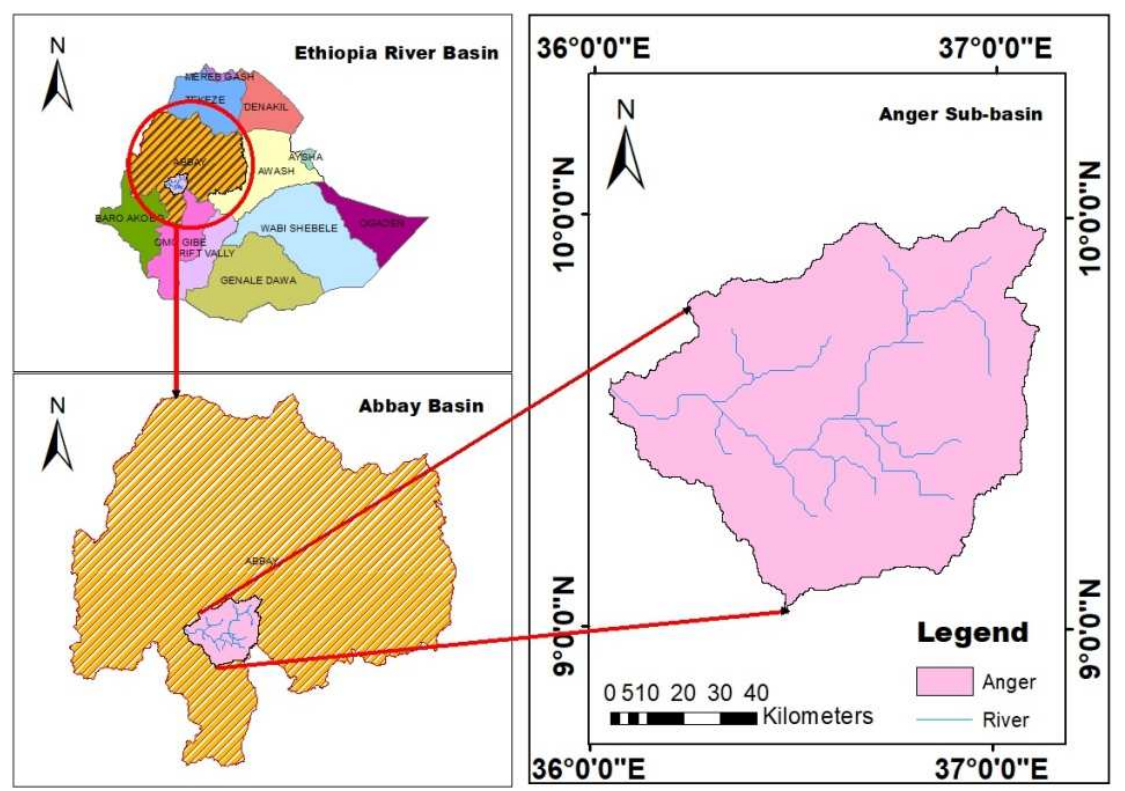

Figure 1. Ethiopian river basin, Abbay Basin and Anger sub basin location map.

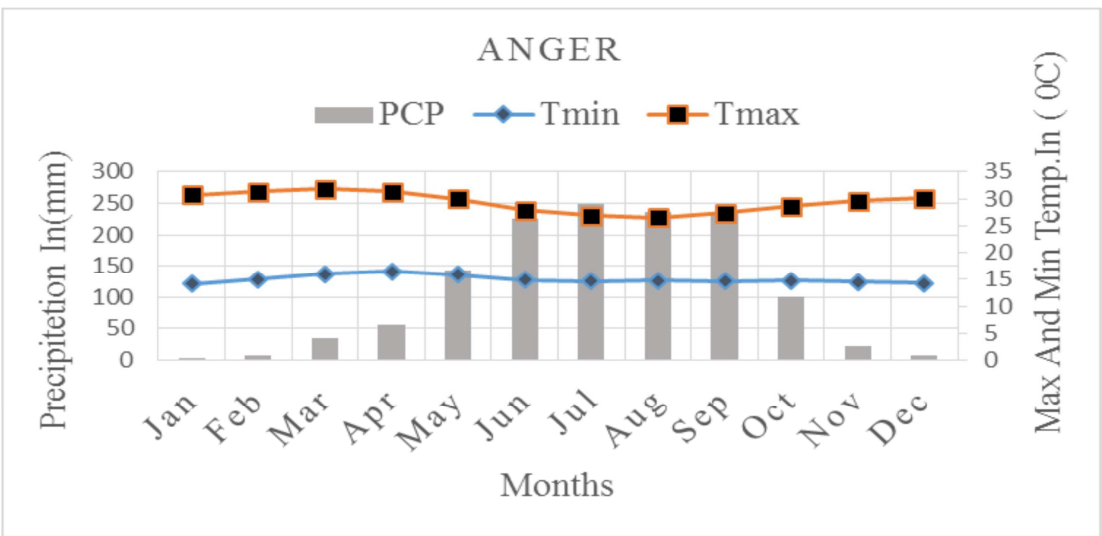

Figure 2. Mean monthly maximum and minimum temperature and rain fall of Anger sub basin. 


\subsection{Methodology}

\subsubsection{SWAT Model Description}

The Soil and Water Assessment Tool (SWAT) is a physical process-based model to simulate continuous-time landscape processes at a catchment scale [5]. The catchment is divided into hydrological response units (HRUs) based on soil type, land use and slope classes that allows a high level of spatial detail simulation.

The major model components include hydrology, weather, soil erosion, nutrients, soil temperature, crop growth, pesticides agricultural management and stream routing [5].

Table 1. Spatial model input data for the Anger Sub watershed.

\begin{tabular}{|c|c|c|c|}
\hline Data type & Description & Resolutions & Sources \\
\hline Topography map & DEM & $30 * 30$ & EMOIE \\
\hline Land use land cover map & Land use land cover classification & $30 * 30$ & GCF \\
\hline Soil map & Soil type & $30 * 30$ & EMOIE \\
\hline Weathers data & Daily precipitation, maximum and minimum temperature, relative humidity, wend speed and sun shine hours. & Five stations & EMA \\
\hline
\end{tabular}

The model predicts the hydrology at each HRU using the water balance equation, which includes daily precipitation, [5].

$$
S W i=S W o+\Sigma(R d a y-Q \operatorname{surf}-E a-W s e e n-Q g w)
$$

Where: -

$\mathrm{SW}_{\mathrm{t}}$ is the final soil water content on a day $\left(\mathrm{mm} \mathrm{H}_{2} \mathrm{O}\right)$ $\mathrm{t}$ is the time (days)

$\mathrm{SW}_{\mathrm{O}}$ is initial soil water content on a day $\mathrm{I}\left(\mathrm{mm} \mathrm{H}_{2} \mathrm{O}\right)$

$\mathrm{R}_{\text {day }}$ is the amount of precipitation on a day $\mathrm{I}\left(\mathrm{mm} \mathrm{H}_{2} \mathrm{O}\right)$

$\mathrm{Q}_{\text {surf }}$ is of the surface runoff on a day I $\left(\mathrm{mm} \mathrm{H}_{2} \mathrm{O}\right)$

$\mathrm{E}_{\mathrm{a}}$ is the evapotranspiration on a day $\mathrm{I}\left(\mathrm{mm} \mathrm{H}_{2} \mathrm{O}\right)$

$\mathrm{W}_{\text {seep }}$ is the amount of water entering the vadose zone from the soil profile on a day $\mathrm{I}\left(\mathrm{mm} \mathrm{H}_{2} \mathrm{O}\right)$

$\mathrm{Q}_{\mathrm{gw}}$ is the amount of return flow on a day $\mathrm{I}\left(\mathrm{mm} \mathrm{H}_{2} \mathrm{O}\right)$

The surface runoff in the Anger sub watershed is estimated by the SWAT model using the SCS curve number method [10].

$$
Q \operatorname{surf}=\frac{\left(R_{d a y}-0.2 S\right)}{(R+0.8 S)}
$$

Where:

$\mathrm{Q}_{\text {surf }}$ is the accumulated runoff or rainfall excess (mm)

$\mathrm{R}_{\text {day }}$ is rainfall depth for the day ( $\mathrm{mm}$ )

$\mathrm{S}$ is retention parameter.

SWAT model provided three options for potential evapotranspiration calculation. Penman Monteith [10], Priestley Taylor [11], and Hargreaves [12] methods. The methods were selected based on data availability.

SWAT model partitions groundwater in to two aquifer systems: a shallow, unconfined aquifer, which contributes return flow to stream within the watershed, and deep, confined aquifer which contributes return flow to streams outside the watershed [13]. SWAT model uses the following equation to simulate ground water for both confined and un confined aquifer.

$$
\begin{gathered}
\text { Aqshi }=\text { aqshi }-1+\text { Wrchrg }- \text { Qgw }- \text { Wrevap }- \\
\text { Wdeep }- \text { Wpumpsh }
\end{gathered}
$$

where: -

Aqshi: the amount of water stored in the shallow aquifer on a day $\mathrm{I}(\mathrm{mm})$,

aqsh i-1: the amount of water stored in the shallow aquifer on day i-1 (mm),

Wrchrg: the amount of recharge entering the aquifer on day I (mm),

Qgw: The ground water flow or base flow, or return flow, in to the main channel

Wrevap: amount of water moving in to soil zone in response to water deficiencies

Wdeep: the amount of water percolating from the shallow aquifer in to the deep aquifer on day I ( $\mathrm{mm})$, and

Wpumpsh: the amount of water removed from the shallow aquifer by pumping

SWAT model have both variable storage and Muskingum methods of flow routing to route the flow of the sub watershed.

$$
\Delta \text { Vstored }=\text { Vin }- \text { Vout }
$$

Where:

$\Delta \mathrm{V}_{\text {stored }}$ is a volume of during the time step $\left(\mathrm{m}^{3}\right)$

$V_{\text {in }}$ is a volume of outflow during the time step $\left(\mathrm{m}^{3}\right)$

$\mathrm{V}_{\text {out }}$ is changed in the volume of storage during the time step $\left(\mathrm{m}^{3}\right)$

\subsubsection{Geographical Information System (GIS)}

Geographical information system (GIS) is the power full model that used for image processing and image classification. To identify change in land use land cover distribution in the Anger watershed over 25-year period from 1986-2010 land sat imageries of seven band were used. during the period of 1986, 2000 and 2010 land sat TM and ETM+ were used respectively. The image data files were downloaded in zipped files from the Global land cover facility (GLCF) website and extracted to Tiff format files. And also, composed the band using the RGB color composition and clip the image covering the complete study area.

Table 2. The acquisition dates, sensor, path row, resolution and producers of the image.

\begin{tabular}{lllll}
\hline Path/row & Acquisition date & Sensor & Resolution (m) & Producer \\
\hline 170/053\&054 & Jan 01, 1986 & TM & 30 & GLCF \\
$170 / 053 \& 054$ & Feb 02, 2000 & ETM+ & 30 & GLCF \\
170/053\&054 & Jan 01 2010 & ETM+ & 30 & GLCF \\
\hline
\end{tabular}




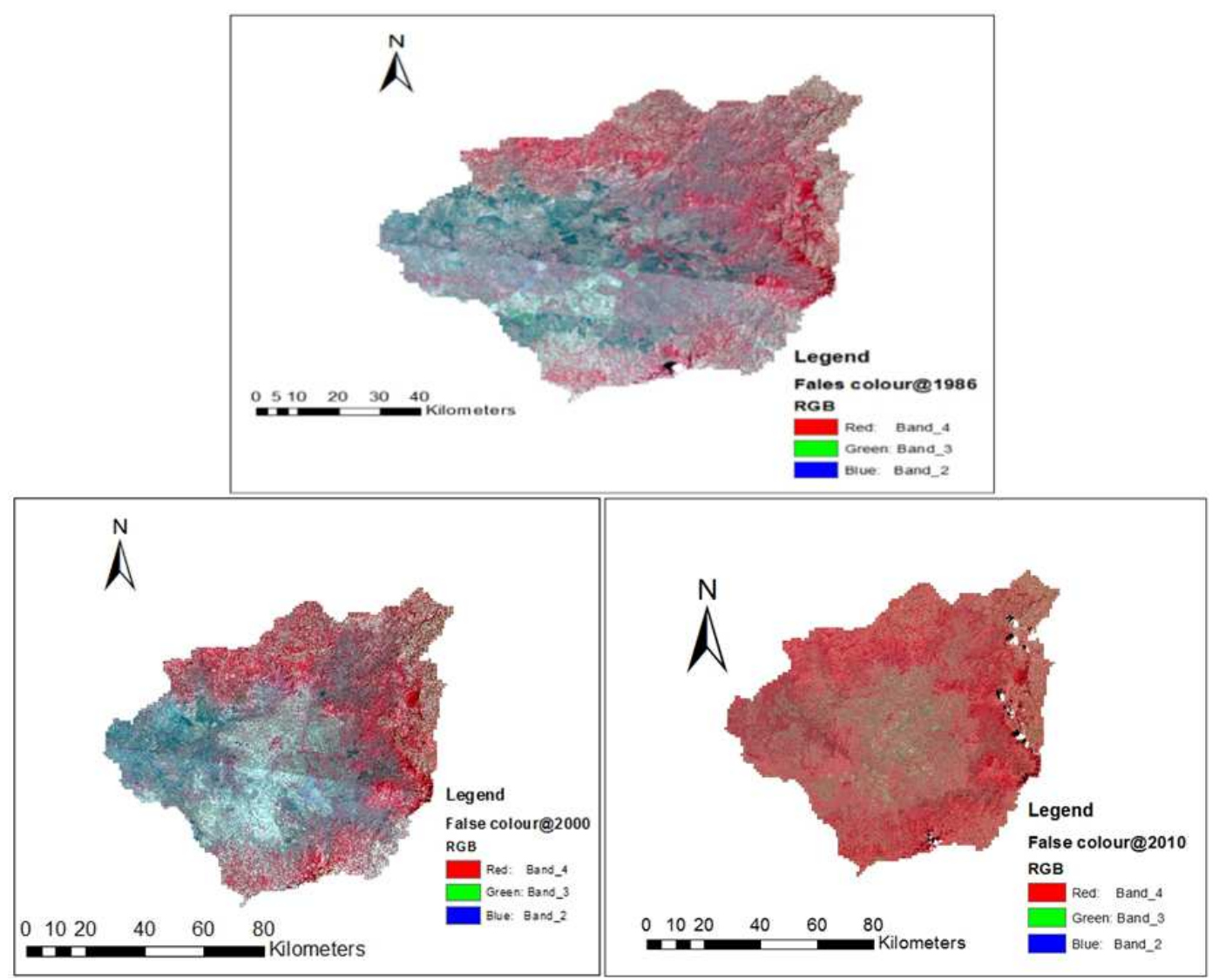

Figure 3. The band composite \& extracted shape file of the Aner sub watershedduring 1986, $2000 \& 2010$.

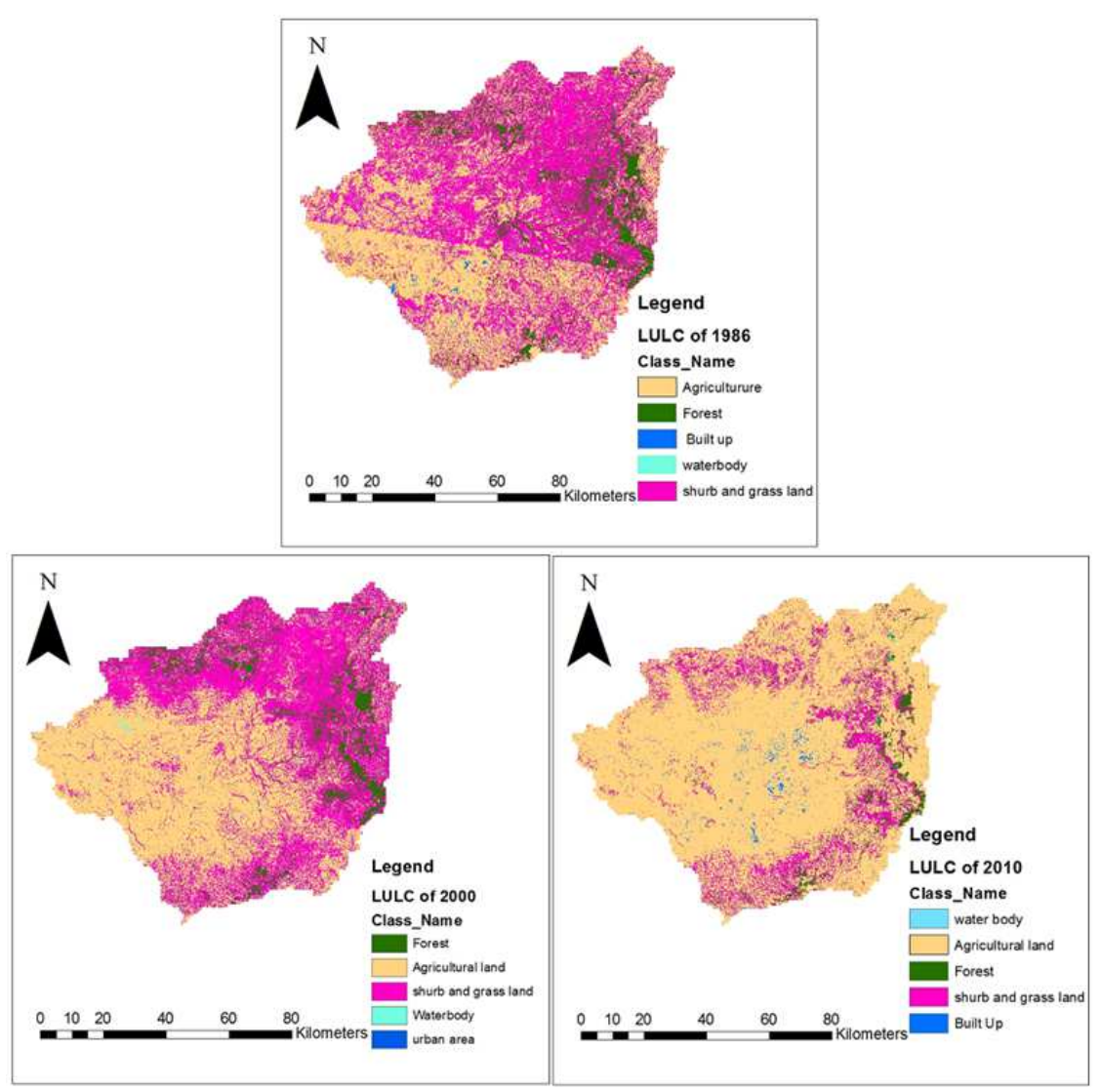

Figure 4. The classified land use/land cover of the Anger sub watershed during 1986, $2000 \& 2010$. 
Image classification is the process of assigning of pixels of continuous raster image to the predefined land-use landcover classes. The result of the classification is mostly affected by various factors such as classification methods, algorithms, collecting of training sites etc.

In remote sensing there are various image classification methods. Those are supervised, unsupervised and hybrid. The supervised classification type was applied for this study and the land cover map was produced based on the pixel based supervised classification thought the step such as: selecting of the training sites which are typically representative for the land-use land-cover classes, image enhancement and image. Using these approaches same training sites were collected as from each image (1986, 2000 and 2010) and perform the classification using the Maximum Likelihood classifier.

Table 3. Land use/Land cover types and area coverage in the Anger sub watershed during 1986, 2000 \& 2010.

\begin{tabular}{|c|c|c|c|c|c|}
\hline Land use land cover type & Description & SWAT code & Area\% 1986 & Area\% 2000 & Area\% 2010 \\
\hline Agricultural land & Agricultural land close to grown & AGRC & 43.2 & 50.9 & 82.5 \\
\hline Shrub and Grass land & Forest deciduous & FRSD & 45.8 & 41.0 & 12.9 \\
\hline Forest & Forest mixed & FRST & 10.3 & 7.2 & 3.6 \\
\hline Built Up & Residential-Low Density & URLD & 0.4 & 0.6 & 0.8 \\
\hline Water body & Water & WATR & 0.4 & 0.2 & 0.1 \\
\hline
\end{tabular}

\subsection{Metrological Data Analysis}

\subsubsection{Filling Missing Data}

Some precipitation stations may have short breaks in the records because of the absence of the observer or because of instrumental failures. It is often necessary to estimate or fill in this missing record. The missing precipitation of a station is estimated from the observations of precipitation at some other stations as close to and as evenly spaced around the station with the missing record as possible. There are methods to fill in missing data. These are the arithmetic mean method, normal ratio method, and inverse distance weighting method. Arithmetic mean method can be used to fill in missing data when normal annual precipitation is within $10 \%$ of the gauge/station for which data are being reconstructed. The normal ratio method is used when the normal annual precipitation at any of the index station differs from that of the precipitation station by more than $10 \%$. In the absence of Normal annual rainfall for the stations, the inverse distance weighting method can be used to fill the missing data. According to [7] the two formulas are described below.

\section{i) Arithmetic Mean Method}

$$
\mathrm{Px}=\frac{1}{n}+\sum_{i=1}^{n=n} * P i
$$

Where $\mathrm{Px}$ is the missing precipitation, $\mathrm{Pi}$ is precipitation at $i^{t h}$ station and $\mathrm{n}$ is the number of nearby stations.

\section{ii) Normal Ratio Method}

$$
\mathrm{Px}=\frac{1}{n}+\sum_{i=1}^{n=n} \frac{N x}{N i} * P i
$$

$\mathrm{P}_{\mathrm{x}}$ is the missing precipitation for any storm at the interpolation station $x$,

$\mathrm{P}_{\mathrm{i}}$ is the precipitation for the same period for the same storm at the $i^{\text {th }}$ station of a group of index stations.

$\mathrm{N}_{\mathrm{x}}$ is the normal annual precipitation for station $x$, and

$\mathrm{N}_{\mathrm{i}}$ is the normal annual precipitation value for the $i^{\text {th }}$ station.

\subsubsection{Data Homogeneity Test}

Homogeneity analysis was used to separate a change in the statistical properties of the time series data. The causes can be either natural or man-made. These include alterations to land use and relocation of the observation gauging station. Therefore, in order to select the representative meteorological station for the analysis of areal rainfall estimation, checking homogeneity of group stations is essential, the homogeneity of the selected gauging stations daily rainfall records was carried out by Non-Dimensional Equation: [8].

$$
P i=\frac{P m i}{P}
$$

Where: $\mathrm{Pi}=$ Non dimensional Value of precipitation for the month $\mathrm{i}$

$\mathrm{P}_{\mathrm{mi}}=$ Over years averaged monthly precipitation for the station i Pi

$P=$ Over year's average yearly precipitation of the station $\mathrm{P}$

According to Homogeneity test analysis, the selected stations were plotted for comparison with each other; for illustration Figure 5. below shows the result of homogeneity analysis result. Same-mode and pattern of the stations are observed and hence group stations selected are homogenous since all the value of Pi are less than 0.3 .

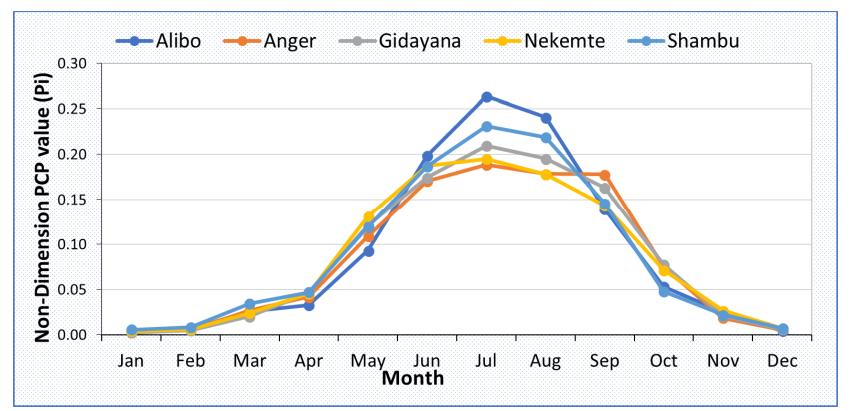

Figure 5. Homogeneity test analysis for all Meteorological stations.

\subsubsection{Data Consistency Test}

The double mass analysis will use for checking the consistency of a hydrological or meteorological record and is 
considered to be an essential tool before taking it for analysis purpose.

The accumulated totals of the gauges are compared with the corresponding totals for a representative group of the nearby gauge. The double mass curve is based on the principle that when each recorded data comes from the same parent population, they are consistent [9] If the cumulative plot of DMC shows different, gradient it should be corrected as:

$$
P c x=P x * \frac{M c}{M a}
$$

Where: $\mathrm{Pcx}=$ Correct precipitation at any time $t_{1}$ at station $\mathrm{x}$

$\mathrm{P}_{\mathrm{x}}=$ Original record precipitation at any time $t_{1}$ at station $\mathrm{x}$

$\mathrm{Mc}=$ Correct slope of the double mass curve and

$\mathrm{Ma}=$ Original slope of double mass curve.

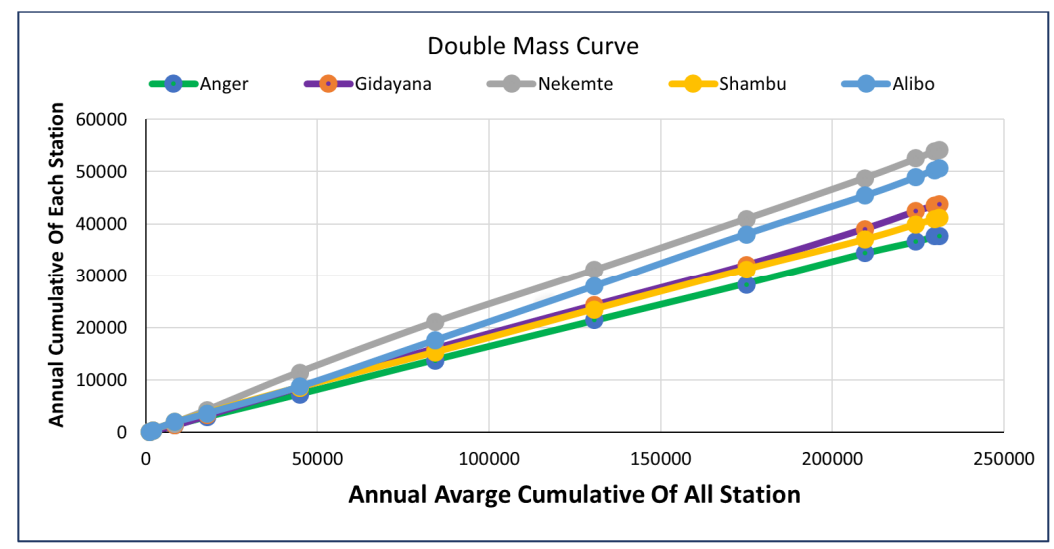

Figure 6. Double mass curve for all metrological stations.

\subsection{Accuracy Assessment}

Accuracy assessment is part of the image classification process and its objective was to evaluate the total number of correctly classified pixels divided by the total number of ground truth pixels. The most widely used classification accuracy is in the form of error matrix which can be used to derive a series of descriptive and analytical statistics [15]. User's accuracy and producer accuracy measured the correctness of each category with respect to errors matrix. The users' accuracy is defined as the probability that a reference pixel has been correctly classified as well as the producer accuracy is defined as the probability that a pixel classified on the map represents that class on the ground.

The accuracy of thematic maps was determined by the constructed matrices along kappa statistics in order to test whether any difference exists in the interpretation. Kappa statistics (Eqn.) considers a measure of overall accuracy of image classification and individual category accuracy as a means of actual agreement between classification and observation. [15] suggested the use of subjective kappa value as $<40 \%$ as poor, $40-55 \%$ fair, $55-70 \%$ good, $70-85 \%$ very good and $>85 \%$ as excellent. The generally the estimate of Kappa was computed as follows:

$$
K a=\frac{P o-P c}{1-P c}
$$

Where, $\mathrm{Po}=$ proportion of observed agreements

$\mathrm{Pc}=$ proportion of agreement expected by chance.

\subsection{Model Performance Evaluation by Using SWAT-CUP}

SWAT-CUP is a public domain program linking the SUFI2 procedure to SWAT. SWAT-CUP provides a decision making frame work that incorporates a semi-distributed approach using both manual and automated calibration incorporating sensitivity and uncertainty analysis. The Sequential Uncertainty Fitting, version 2 (SUFI-2) is one of the uncertainty analyses programs that is incorporated in an independent program called SWAT calibration and Uncertainty Program (SWAT-CUP) [6], that perform uncertainty analysis due to both parameter and model uncertainties. Its main function is to calibrate SWAT and perform validation, sensitivity and uncertainty analysis for a watershed model created by SWAT. SUFI-2 is developed for a combined calibration and uncertainty analysis to find parameter uncertainties while calculating smallest possible prediction uncertainty band. In SUFI-2, parameter uncertainty accounts for all sources of uncertainties such as uncertainty in driving variables (e.g., rainfall), parameters, conceptual model, and measured data (e.g., observed flow, sediment) [6].

The performance SWAT was evaluated using the statistical measures to determine the quality and reliability of simulate when compare to observed values. The performance of model in simulating stream flow and sediment yield is evaluated using SWAT-CUP. The selection and use of specific efficiency criteria and the interpretation of the results can be a challenge for even the most experienced hydrologist since each criterion may place different emphasis on different types of simulated and observed behaviors. For this study coefficient of determination $\left(\mathrm{R}^{2}\right)$ and Nash-Sutcliffe Efficiency (NSE) was choose for the criteria of model performance.

i. Coefficient of Determination $\left(R^{2}\right)$ : is an indicator of strength of relationship between observed and simulation value. Coefficient determination ranges 
from 0 to 1 , with higher values indicating less error variance, and typically values greater than 0.5 are considered acceptable [14].

The following formula used to calculate $\mathrm{R}^{2}$ :

$$
R^{2}=\frac{\sum_{i=1}^{n}(O i-O m) *(S i-S m)}{\sqrt{\sum_{i=1}^{n}\left((O i-O m)^{2}\right)} * \sqrt{\sum_{i=1}^{n}\left((S i-S m)^{2}\right)}}
$$

Where:

$\mathrm{R}^{2}$ is coefficient of determination,

Oi is observed hydrologic variable,

$\mathrm{Om}$ is mean observed hydrologic variable,

$\mathrm{Si}$ is model simulated output,

$\mathrm{Sm}$ is mean of the model simulations and

$\mathrm{N}$ is total number of observations.

ii. Nash-Sutcliffe Efficiency (NSE): is determines the relative magnitude of the residual variance compared to the measured data variance is calculated as follows.

$$
N S E=\frac{\sum_{i=1}^{n}\left((O i-S i)^{2}\right)}{\sum_{i=1}^{n}\left((O i-O m)^{2}\right)}
$$

Where:

$\mathrm{S}$ is model simulated output,

$\mathrm{O}$ is observed hydrologic variable,

Om is mean of the observations that NSE uses as a benchmark against which performance of the hydrologic model is compared and $\mathrm{n}$ is total number of observations.

NSE indicates how well the plot of observed versus simulated data fits the one ratio to one line. According to [14] NSE ranges from negative infinity to 1.0 , where NSE is 1.0 shows that a perfect model. NSE 0.0, implies the observed mean is as good a predictor as the model. Generally, the value between 0.0 and 1.0 acceptable model performance where below 0.0 is not acceptable performance and the model simulation can be judged a satisfactory if NSE $>0.50$

\subsubsection{Root Mean Square Error Observation Standard Deviation Ratio (RSR)}

RSR varies from the optimal value of " 0 ", which indicate zero roots mean square error (RMSE) or residual variation and therefore perfect model simulation, to a large positive value. Generally, if the value of RSR $\leq 0.70$ the model simulation can be considered as satisfactory [15].

$$
\operatorname{RSR}=\frac{\sqrt{\sum_{i=1}^{n}\left((O i-S i)^{2}\right)}}{\sqrt{\sum_{i=1}^{n}\left((O i-S m)^{2}\right)}}
$$

Where:

Si is model simulated output;

Oi is observed hydrologic variable and

$\mathrm{Sm}$ is mean of the model simulations.

\subsubsection{Percent Bias (PBIAS)}

PBIAS is the deviation of data being evaluated, expressed as a percentage. If PBIAS $\pm 25 \%$ for streamflow and PBIAS $\pm 55 \%$ for sediment, the model simulation can be judged as satisfactory.

$$
N S E=\frac{\sum_{i=1}^{n}\left((O i-S i)^{2}\right) * 100}{\sum_{i=1}^{n} O i}
$$

Where:

$\mathrm{Si}$ is model simulated output,

Oi is observed hydrologic variable.

\subsection{Over All Methodology}

The following framework illustrates the general workflow of the study

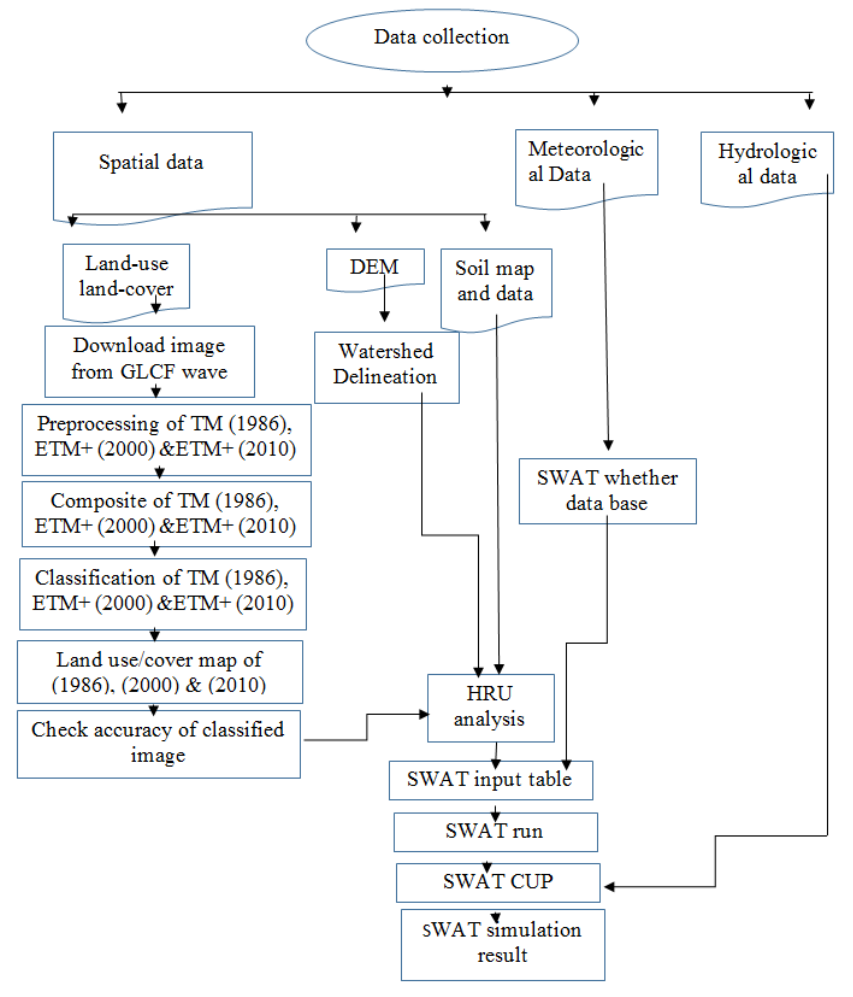

Figure 7. General framework of the study.

\section{Result and Discussion}

\subsection{Accuracy Assessment}

The accuracy assessment is used to identify the precision of the classified image. It was evaluated by using both the original mosaic image and the Google Earth image as a reference. Therefore, the following randomly selected points 130,131 and 141 were used for validation during the year of 1986, 2000 and 2010 images respectively. Tables 4, 5 and 6 show a confusion matrix for the three Landsat images.

\subsubsection{Overall Accuracy}

The overall accuracy was achieved by dividing the total number of accurate pixels by the total number of pixels in the confusion matrix. For the maps of 1986, 2000 and 2010 the result was $88 \%, 87 \%$ and $92 \%$ respectively. According to [15], the minimum accuracy value for reliable land cover classification is $85 \%$.

\subsubsection{Kappa Coefficient}

The kappa coefficient gives the agreement between classified 
image and reference or ground truth. A kappa coefficient equal to 1 means perfect agreement where as a value close to zero means that the agreement is no better than would be expected by chance. The results indicated that the kappa coefficient for the maps of 1986, 2000 and 2010 were $81 \%, 79.5 \%$ and $83.2 \%$ respectively. Therefore, based on tables 4, 5 and 6 the classification carried out in this study produces a kappa coefficient with substantial agreement for the year 2000 and almost prefect agreement for year 1986 and 2010.

\subsubsection{Producer's Accuracy}

The producer's accuracy was found by dividing the number of properly classified pixels in the class by the total number of pixels of the class in the reference data. Its overall result ranges from $58 \% \%$ to $100 \%$. The lowest values were achieved due to misclassified of different land-use land-cover classes.

\subsubsection{User's Accuracy}

The User's accuracy was the ratio between the total number of pixels properly fitting to a class and the total number of pixels allocated to the same class. its overall accuracy ranges from $78 \%$ to $100 \%$. The lowest value was achieved due to misclassified because of the similarity spectral properties of forest and water body.

Table 4. Confusion matrix for classified land use land cover during 1986.

\begin{tabular}{|c|c|c|c|c|c|c|c|c|}
\hline & & \multicolumn{7}{|c|}{ Ground truth Data } \\
\hline & & AGL & FL & BU & WB & SL & Grand Total & User's Accuracy \\
\hline \multirow{5}{*}{ Classification Data } & AGL & 48 & 1 & & & 2 & 51 & $94 \%$ \\
\hline & FL & 1 & 10 & & & 1 & 12 & $83 \%$ \\
\hline & BU & 1 & & 4 & & & 5 & $80 \%$ \\
\hline & WB & 1 & & & 5 & & 6 & $83 \%$ \\
\hline & SL & 7 & 2 & & & 47 & 56 & $84 \%$ \\
\hline Grand Total & & 58 & 13 & 4 & 5 & 50 & 130 & \\
\hline Producer's Accuracy & & $83 \%$ & $77 \%$ & $100 \%$ & $100 \%$ & $94 \%$ & & Overall Accuracy $=88 \%$ \\
\hline
\end{tabular}

Kappa coefficient $=81 \%$.

Note: $\mathrm{AGL}=$ Agricultural land; $\mathrm{WB}=$ Water Body; $\mathrm{FL}=$ Forest land, $\mathrm{SL}=$ Shrub land; $\mathrm{BU}=$ Built Up.

Table 5. Confusion matrix for classified land use land cover during 2000.

\begin{tabular}{|c|c|c|c|c|c|c|c|c|}
\hline & & \multicolumn{7}{|c|}{ Ground truth Data } \\
\hline & & FL & AGL & SL & WB & BU & Grand Total & User's Accuracy \\
\hline \multirow{5}{*}{ Classification Data } & FL & 8 & 1 & & & & 9 & $89 \%$ \\
\hline & AGL & 3 & 54 & 5 & & & 62 & $87 \%$ \\
\hline & SL & 2 & 4 & 43 & & 1 & 50 & $86 \%$ \\
\hline & WB & & & 1 & 4 & & 5 & $80 \%$ \\
\hline & $\mathrm{BU}$ & & & & & 5 & 5 & $100 \%$ \\
\hline Grand Total & & 13 & 59 & 49 & 4 & 6 & 131 & \\
\hline Producer's Accuracy & & $62 \%$ & $92 \%$ & $88 \%$ & $100 \%$ & $83 \%$ & & Overall Accuracy $=87 \%$ \\
\hline
\end{tabular}

Kappa coefficient $=79.5 \%$.

Note: $\mathrm{AGL}=$ Agricultural land; $\mathrm{WB}=$ Water Body; $\mathrm{FL}=$ Forest land, $\mathrm{SL}=$ Shrub land;

$\mathrm{BU}=$ Built $\mathrm{Up}$.

Table 6. Confusion matrix for classified land use land cover during 2010

\begin{tabular}{|c|c|c|c|c|c|c|c|c|}
\hline & & \multicolumn{7}{|c|}{ Ground truth Data } \\
\hline & & WB & AGL & FL & SL & BU & Grand Total & User's Accuracy \\
\hline \multirow{5}{*}{ Classification Data } & WB & 4 & & & & & 4 & $100 \%$ \\
\hline & AGL & & 97 & 3 & 1 & 1 & 101 & $96 \%$ \\
\hline & FL & 1 & 1 & 7 & & & 9 & $78 \%$ \\
\hline & SL & & 1 & 3 & 18 & & 22 & $82 \%$ \\
\hline & $\mathrm{BU}$ & & 1 & & & 4 & 5 & $80 \%$ \\
\hline Grand Total & & 5 & 100 & 12 & 19 & 5 & 141 & \\
\hline
\end{tabular}

Kappa coefficient $=83.2 \%$.

Note: $\mathrm{AGL}=$ Agricultural land; $\mathrm{WB}=$ Water Body; $\mathrm{FL}=$ Forest land, $\mathrm{SL}=$ Shrub land; $\mathrm{BU}=$ Built Up.

\subsection{Land Use Land Cover Change Analysis}

The maps of the year 1986, 2000 and 2010 were generated from the land sat TM and ETM+ imaginary. The classified land-use land-cover of the watershed shown that there is an increasing of agricultural land and built-up area. And also, decreasing of forest, shrub, grassland and water bodies. In general, during 25-year period the agricultural land was increased by $39.3 \%$ whereas the Shrub and grass land decreased by $32.9 \%$ and also forest area decreased by $6.6 \%$. 


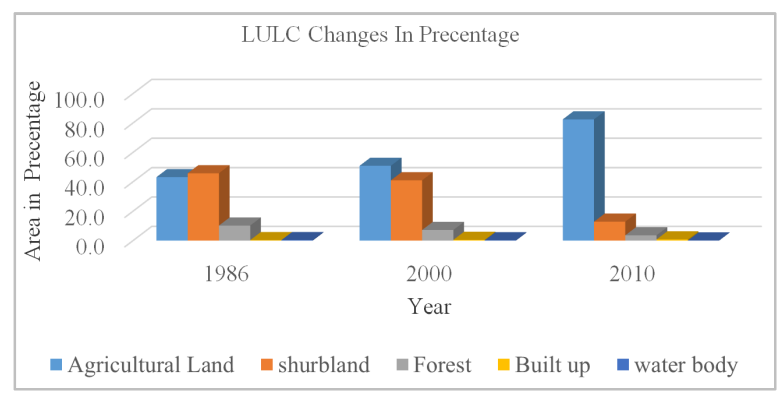

Figure 8. Land use land cover change during 25-year period.

Table 7. Land-use Land-cover change from 1986 to 2010

\begin{tabular}{llll}
\hline Land-use Land-cover & \multicolumn{3}{l}{ LULC Area Change in\% } \\
\cline { 2 - 4 } Type & $\mathbf{2 0 0 0 - 1 9 8 6}$ & $\mathbf{2 0 1 0 - 2 0 0 0}$ & $\mathbf{2 0 1 0 - 1 9 8 6}$ \\
\hline Agricultural Land & 7.7 & 31.6 & 39.3 \\
Shrub land & -4.8 & -28.1 & -32.9 \\
Forest & -3.0 & -3.6 & -6.6 \\
Built up & 0.2 & 0.3 & 0.5 \\
Water body & -0.2 & -0.1 & -0.3 \\
\hline
\end{tabular}

Table land use land cover type and area coverage change in $\%$ during 25-year.

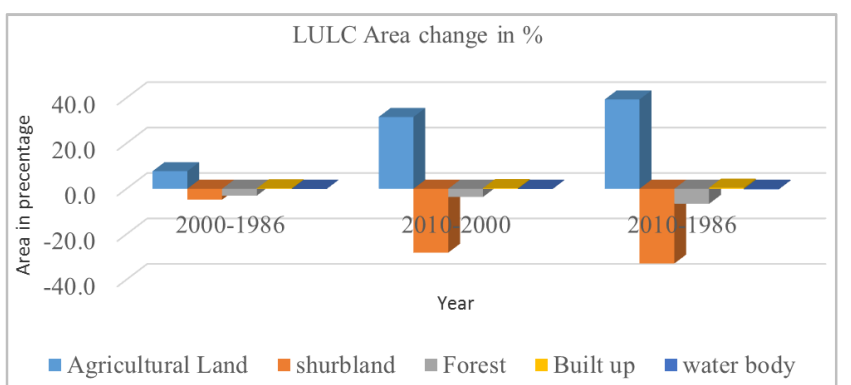

Figure 9. Land use land cover Area change in percentage during 25-year period.

\subsection{Stream Flow Modeling}

\subsubsection{Sensitivity Analysis}

The simulated stream flow for the watershed was evaluated by using the monthly observed flow data for identifying the most sensitive parameter and for further calibration of the SWAT model. Twenty-six flow parameters were checked for sensitivity and seven of them were found to be highly sensitive. For, detail information presented in (Table 8) below.

Table 8. Sensitive parameters and their rank with $t$-stat and $p$-value for stream flow.

\begin{tabular}{llllll}
\hline Parameter Name & Sensitivity rank & t-Stat & P-Value & Fitted-value & Min-value \\
\hline 4: V_CH_N2. rte & 7 & -0.49 & 0.62 & 0.1125 & 0 \\
5: V_CH_K2. rte & 6 & 0.66 & 0.51 & 126.875 & 5 \\
6: V_ALPHA_BNK. rte & 5 & 0.87 & 0.39 & 0.925 & 0 \\
3: V_ESCO. hru & 4 & 1.14 & 0.26 & 0.925 & 130 \\
7: R_HRU_SLP. hru & 3 & 1.57 & 0.12 & 0.195 & 0.8 \\
1: R_CN2. mgt & 2 & 2.36 & 0.02 & 0.0125 & 0 \\
2: V_GW_DELAY.gw & 1 & -3.78 & 0.00 & 145.5 & -0.25 \\
\hline
\end{tabular}

From those parameters Groundwater delay (GW_DELAY), SCS runoff curve number (CN2), Average slope steepness (HRU_SLP), Soil evaporation compensation factor (ESCO), Base flow alpha factor for bank storage
(ALPHA_BNK), Channel effective hydraulic conductivity $\left(\mathrm{CH}\right.$ _K2) and Manning's value for main channel $\left(\mathrm{CH}_{-} \mathrm{N} 2\right)$ were sensitive and ranked from 1 up to 7 respectively.

\section{Calibration From(1990-1999)}

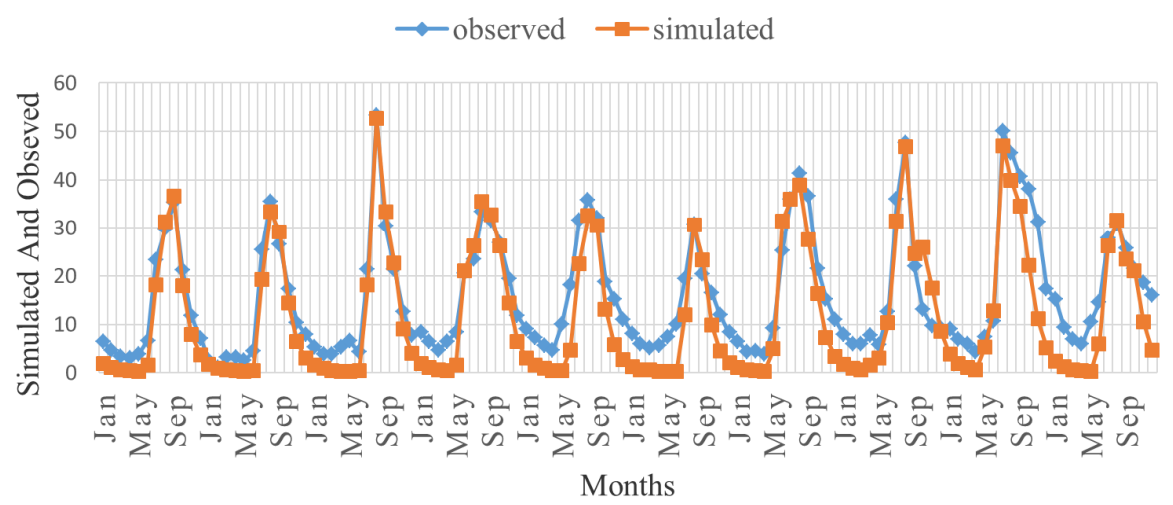

Figure 10. Calibration of stream flow from (1990-1999).

\subsubsection{Flow Calibration}

The simulated and observed stream flow had a good agreement with the default value of parameters in Anger watershed. After sensitivity analysis has been done, the calibration of stream flow was done manually and Auto calibration respectively for the period of 10 years from 19901999. The result of agreement between observed and simulated stream flow (Figure 10) shown by statical determinant with value of NSE, $\left(\mathrm{R}^{2}\right) 0.76$ and 0.90 respectively. 


\subsubsection{Uncertainty}

It is necessary to consider uncertainties in predicting stream flow of the watershed. There are different sources of uncertainties. Those Sources of uncertainty are: -Input and Output data.

\subsubsection{Model Validation}

After calibration, validation was carried out for 6 years i.e from 2000-2005 were performed. The model validation also showed a good agreement between simulated and observed monthly flow as shown (Figure 11) with the NSE, $\mathrm{R}^{2}$ of 0.63 0.84 respectively.

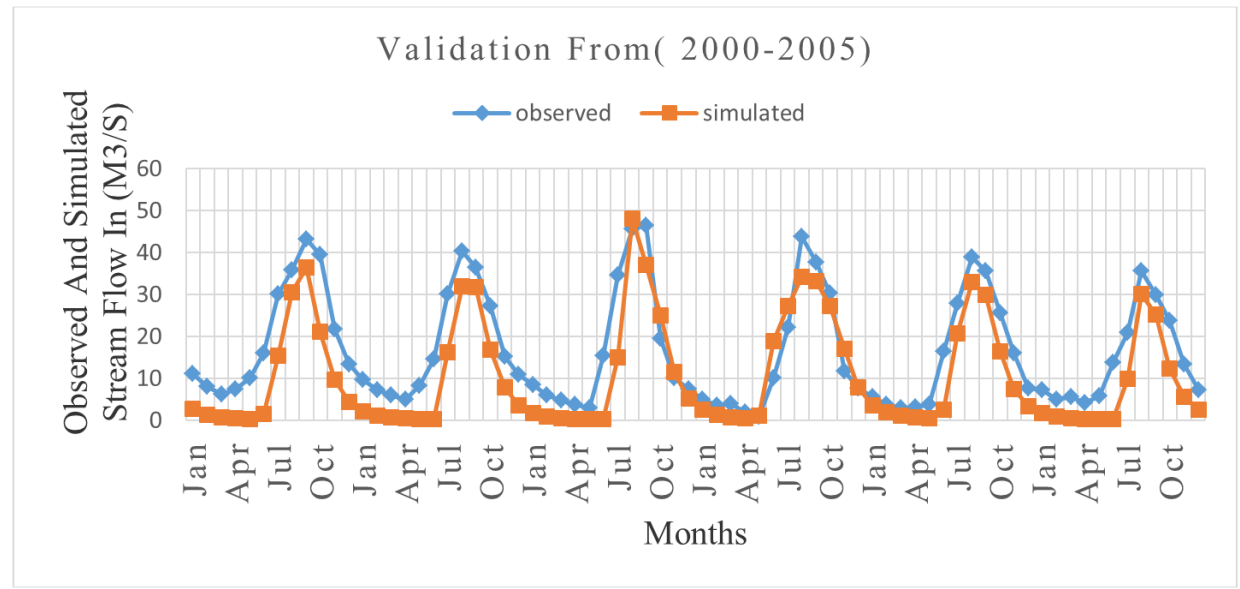

Figure 11. Validation of stream flow from (2000-2005).

Table 9. Average monthly stream flow for calibration and validation.

\begin{tabular}{|c|c|c|c|c|c|}
\hline \multirow{6}{*}{$\begin{array}{l}\text { During } \\
\text { calibration (1990- } \\
1999)\end{array}$} & Season & Observed flow $\left(\mathrm{m}^{3} / \mathrm{s}\right)$ & Simulated flow $\left(\mathrm{m}^{3} / \mathrm{s}\right)$ & $\mathbf{R}_{2}$ & ENS \\
\hline & DJF (Belg) & 15.94 & 14.74 & \multirow{5}{*}{0.90} & \multirow{5}{*}{0.76} \\
\hline & MAM (Bega) & 11.92 & 11.10 & & \\
\hline & JJA (kiremt) & 51.48 & 50.87 & & \\
\hline & SON (Tsedey) & 43.93 & 42.90 & & \\
\hline & Annually & 30.82 & 29.90 & & \\
\hline \multirow{6}{*}{$\begin{array}{l}\text { During Validation } \\
(2000-2005)\end{array}$} & Season & Observed flow $\left(\mathrm{m}^{3} / \mathrm{s}\right)$ & Simulated flow $\left(\mathrm{m}^{3} / \mathrm{s}\right)$ & $\mathrm{R}_{2}$ & ENS \\
\hline & DJF (Belg) & 14.86 & 14.08 & & \multirow{5}{*}{0.63} \\
\hline & MAM (Bega) & 9.52 & 9.09 & \multirow{4}{*}{0.84} & \\
\hline & JJA (kiremt) & 54.00 & 52.22 & & \\
\hline & SON (Tsedey) & 54.15 & 53.55 & & \\
\hline & Annually & 33.13 & 32.24 & & \\
\hline
\end{tabular}

\subsection{Land-Use Land-Cover Change Impact Analysis}

Effects of land-use land-cover change on average annual surface runoff of Anger sub watershed shown that surface runoff volume increased due to land use land cover change from 1986 to 2000 by $12.54 \mathrm{Mm}^{3}$, from 2000 to 2010 by
$25.59 \mathrm{Mm}^{3}$ and from 1986 to 2010 by $38.13 \mathrm{Mm}^{3}$ respectively. Increasing in stream flow showed more variation at the seasonal time step with a range of $0.3 \mathrm{Mm}^{3}$ to $32.16 \mathrm{Mm}^{3}$ from 1986 to $2000,0.16 \mathrm{Mm}^{3}$ to $60.36 \mathrm{Mm}^{3}$ from 2000 to 2010 and $-0.13 \mathrm{Mm}^{3}$ to $92.52 \mathrm{Mm}^{3}$ from 1986 to 2010.

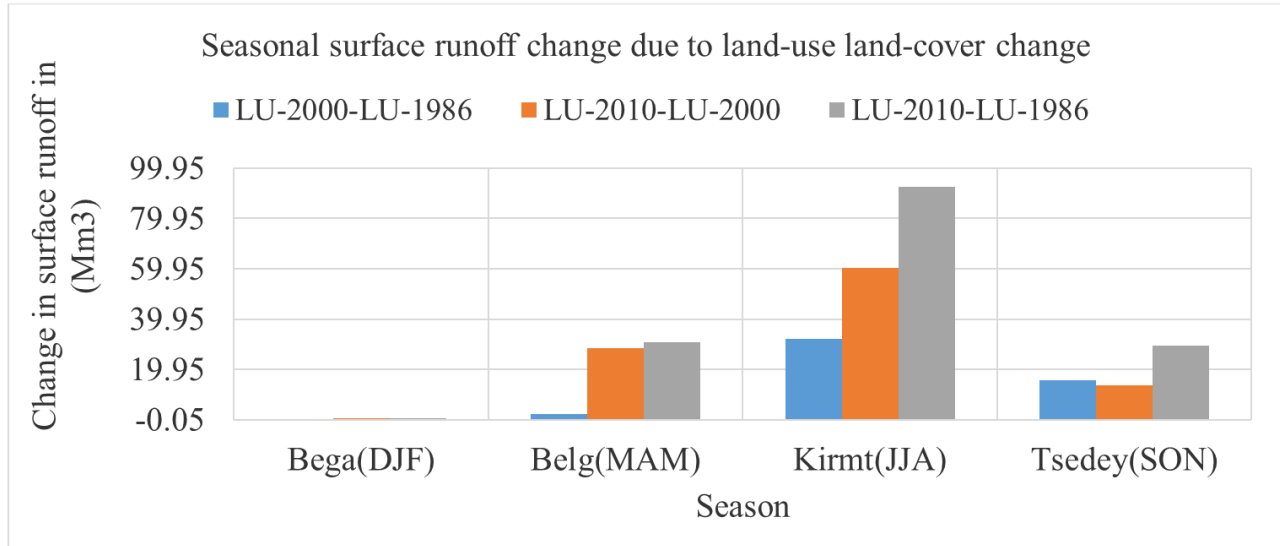

Figure 12. Seasonal surface runoff change due to Land use land cover changes. 
The effect of land use land cover change on average annual Water yield of Anger sub watershed shown that Water yield volume decreased due to land use land cover change from 1986 to 2000,2000 to 2010 and 1986 to 2010 were $22.16 \mathrm{Mm}^{3}, 20.76 \mathrm{Mm}^{3}$ and $1.40 \mathrm{Mm}^{3}$ respectively.
Increasing and decreasing Water yield showed more variations at the seasonal time step with a range of -63.26 $\mathrm{Mm}^{3}$ to $27.35 \mathrm{Mm}^{3}$ in 1986 to $2000,0.13 \mathrm{Mm}^{3}$ to $33.41 \mathrm{Mm}^{3}$ in 2000 to 2010 and $-63.13 \mathrm{Mm}^{3}$ to $60.76 \mathrm{Mm}^{3}$ in 1986 to 2010 .

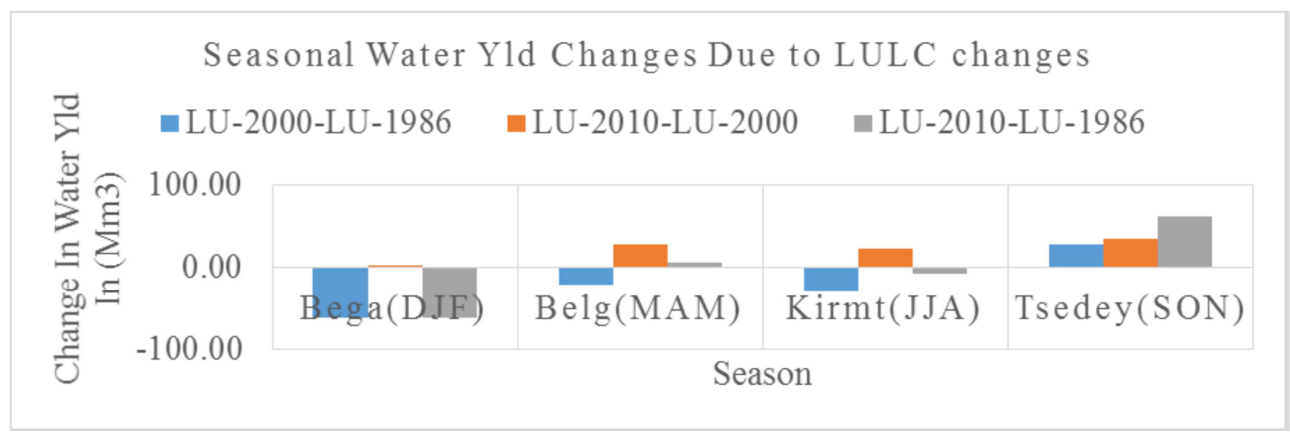

Figure 13. Seasonal water Yld change due to LULC change.

\section{Conclusion}

In Anger sub watershed, the SWAT model was used to simulate the effect of past land use land cover change on runoff volume change and Arc GIS was used to process preliminary data, extract, layer stake, mosaic satellite images, and image classification. Performance of the model was confirmed, with a NSE and $\mathrm{R}^{2}$.

Due to the effect of urbanization, deforestation and agricultural expansion the past land use land cover changes increased runoff volume of the sub-basin by $12.54 \mathrm{Mm}^{3}$, $25.29 \mathrm{Mm}^{3}$ during 1986-2000 and 2000-2010 respectively.

As research findings shown that, much of the original forest in the sub watershed has already converted to agricultural lands, for instance agricultural land increased by $39.3 \%$ and built-up area increased by $0.5 \%$ and also, shrubland, forest area, and water body decreased by $32.9 \%, 6.6 \%$, and $0.3 \%$ respectively. These changes would have aggravated problem related to water scarcity in dry period and hill-slope erosion during wet period

The accuracy of LULC Classification was achieved by: overall accuracy, user's accuracy, and producer's accuracy and kappa coefficient. The kappa coefficient shows good agreement between classified image and ground truth with $81 \%, 79.5 \%$ and $83.2 \%$ during 1986, 2000 and 2010 respectively.

\section{Acknowledgements}

The authors would like to thank: The Wollega University, College of Engineering and Technology, Department of Hydraulic and Water Resource Engineering Ethiopia, for providing funding for this research work; the Ministry of Water Resources of Ethiopia for providing the hydrological and GIS data; and the National Meteorological Service Agency of Ethiopia for providing weather data. Nameless reviewers are also thanked for their constructive comments and suggestions that helped in improving this paper.

\section{References}

[1] IPCC. (2013). The Physical Science Basis: Contribution of working group I to the fifth assessment report of Intergovernmental Panel on climate change. Cambridge University Press; Cambridge, UK and New York, NY.

[2] Elfert. S., and Bormann. H. (2010). Simulated impact of past and possible future land use changes on the hydrological response of Northern German lowland 'Hunte' catchment. Journal of Hydrology, 383, 245-255.

[3] Pechlivanidis I. G., J. B. (2011). Catchment scale hydrological modelling. A review of model types, calibration approaches and uncertainty analysis methods in the context of recent developments in technology and applications, Global NEST Journal, 13, 193-214.

[4] Yang, J. R. (2008). Comparing uncertainty analysis techniques for a SWAT application to the Chaohe Basin in China. $J$. Hydrol., 358, 1-23.

[5] Neitsch, S. A. (2005). Soil and Water Assessment Tool, Theoretical documentation: Version 2005. Temple, TX. USDA Agricultural Research Service and Texas $A \& M$ Black land Research Centre.

[6] Abbaspour, K. J. (2007). Estimating Uncertain Flow and Transport Parameters Using a Sequential Uncertainty Ftting Procedure. Vadose Zone Journal, 3 (4), 1340-1352.

[7] Richards, H. M. (1998). Hydrologic Analysis and Design. Department of Civil Engineering, University of Mryland, Prentice Hall Upper Saddle River, New Jersey 074582nd Edition.

[8] Tadesse T. (2016). Development of Water Allocation and Utilization System for Koka Reservoir under Climate Change and Irrigation Development Scenarios (Case Study Downstream of Koka Dam to Metahara). Addis Ababa Ethiopia, page 28.

[9] Subramanya, K. (2008). Engineering Hydrology, Third Edition book, Kanpur Indian Institute of Technology. 
[10] Monteith, J. (1965). Evaporation and the Environment. In the state and movement of water in living Organisms, sixth Symposium. Soc. For Exp. Biol. Swansea,. Cam-bridge University Press.

[11] Priestley, C. H. (1972). On the Assessment of Surface Heat Flux and Evaporation using large scale parameters. Division of Atmospheric Physics, Commonwealth Scientific and Industrial Research Organization, Aspendale, Victoria, Australia.

[12] Hargreaves, G. a. (1985). Agricultural benefits for Senegal River Basin. Journal of Irrig. and Drain. Engr., 111 (2), 113124.
[13] Arnold J. G. et al., A. P. (1993). A comprehensive surfaceground water from model. Journal of Hydrology.

[14] Morias D. N. et al. (2007). Model Evaluation Guidelines for Systematic Quantification of Accuracy i Water Simulation. 885-900.

[15] Manandhar, R. O. (2009). Improving the Accuracy of Land use Land cover Classification of Landsat Data Using Postclassification Enhancement. 